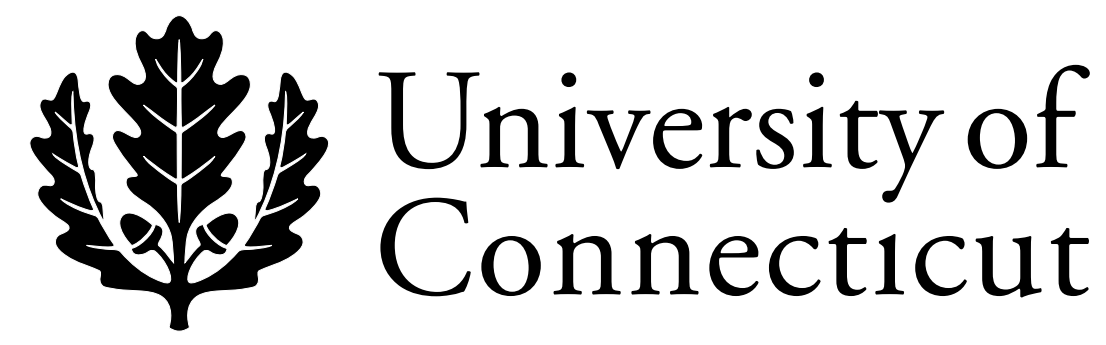

Department of Economics Working Paper Series

Voluntary Agreements with Industries: Participation Incentives with Industry-wide Targets

Na Li Dawson

PriceWaterhouseCoopers

Kathleen Segerson

University of Connecticut

Working Paper 2004-06

November 2003

341 Mansfield Road, Unit 1063

Storrs, CT 06269-1063

Phone: (860) 486-3022

Fax: (860) 486-4463

http://www.econ.uconn.edu/ 


\begin{abstract}
There is an increasing interest in the use of voluntary approaches to environmental protection as an alternative to more traditional regulatory approaches. In many cases, entire industries are faced with possible imposition of costly environmental policies if environmental goals are not met voluntarily. If the threat is industry-wide, a potential free-rider problem exists since, if the environmental goal is met by others, individual firms would benefit from avoidance of the costly policy without incurring the associated cost. We develop a multiple-firm model of an industry's voluntary adoption of environmental protection measures to achieve a predetermined industry-wide emissions reduction target under an explicit threat of imposition of an emissions tax. We examine the free-riding incentive of individual firms and its impact on the viability of a voluntary approach to pollution control (VA). We find that despite the free-riding problem, there is an incentive for a sub-group of firms in an industry to participate in a VA. A VA is strictly preferred by the industry as a whole (aggregate industry profits are higher), although it is cost inefficient from society's point of view.
\end{abstract}

Journal of Economic Literature Classification: K32, D21, Q28

Keywords: Voluntary agreement, Voluntary approach, environmental protection, free-riding, emissions tax 


\section{Voluntary Agreements with Industries Participation Incentives with Industry-wide Targets}

\section{Introduction}

Since the early 1970 s, policymakers have relied heavily on regulation as a means of controlling the emissions of environmental pollutants. These regulations have been widely criticized for being costly and inefficient. In response, policymakers have begun to search for alternative policies that allow environmental protection goals to be met at lower cost. One alternative is to move toward the use of incentive or market-based policy instruments, e.g. emission taxes or marketable permits. Another alternative that has attracted policymakers' attention is increased reliance on voluntary environmental protection. ${ }^{2}$ Since the early 1990s, hundreds of voluntary agreements (VAs) have been signed throughout the world, many of them in the European Community (see Commission of the European Communities (CEC), 1996; European Environmental Agency (EEA), 1997; Organisation for Economic Co-operation and Development (OECD), 1999).

While many voluntary agreements are between regulators and individual firms, ${ }^{3}$ often there is an explicit or implicit agreement between regulators and a group of firms or an industry. Examples include the French agreement on the treatment of End-of-Life Vehicles (ELV) (Lévêque and Nadaï, 1995; EEA, 1997; Aggeri and Hatchuel, 1999), the Norwegian waste agreements (Nyborg, 2000), and the German industry and trade associations' voluntary declaration on $\mathrm{CO}_{2}$ reduction (Lévêque and Nadaï, 1995; EEA, 1997; Jochem and Eichhammer, 1999). 
To be successful, a voluntary approach must have a sufficiently strong incentive for firm participation, i.e., firms must in some way benefit from undertaking voluntary measures. Firms can benefit from adopting voluntary measures if a proactive environmental strategy allows them to exploit a market for environmentally-friendly products or generate firm-specific public goodwill (Smart, 1992; Arora and Gangopadhyay, 1995; Esty, 1997; Khanna and Damon, 1999). Alternatively, firms might voluntarily undertake pollution abatement if, by adopting voluntary measures, they can avoid more costly government policies that might be imposed. If the threatened government policy is a regulation with limited flexibility, firms can benefit from the increased flexibility that might accompany a voluntary approach. ${ }^{4}$ If the threatened policy is an emissions tax, firms can benefit by avoiding the tax payments. For example, the voluntary agreements involving the German energy sector were prompted by threats of imposition of a carbon tax (EEA, 1997; Jochem and Eichhammer, 1999). Similarly, voluntary agreements in Norway resulted from threats regarding imposition of a tax on packaging materials (Nyborg, 2000).

While threats of the imposition of regulation or emissions taxes can be effective in providing participation incentives, when applied to an entire industry they suffer from a potentially serious drawback, namely, the incentive for individual firms to free-ride. If the industry can avoid the regulation or tax with less than full participation, then firms that do not participate can enjoy the benefits of avoiding the costly policy without the associated costs. Although some have argued that industry associations will find means to solve the free-rider problem (e.g., Nyborg, 2000), a recent survey of voluntary approaches by the European Environmental Agency suggests that this may not always be 
true. It notes that "Direct involvement through a trade association generally tends to display a high degree of free riding by SMEs [small and medium enterprises]. Although this might not significantly affect the environmental performance of the agreement, it is of concern to its stability - i.e., the actions of SMEs in free riding might jeopardise the whole agreement" (EEA, 1997, p. 47). Thus, an important policy question is whether this free-rider incentive, in fact, undermines the viability of a voluntary approach.

To date, the economic literature on voluntary approaches has focused primarily on single-firm models that do not allow for free-riding (e.g., Stranlund, 1995; Wu and Babcock, 1995, 1996; Cavaliere, 1998; Segerson and Miceli, 1998, 1999). ${ }^{5}$ Two recent papers that examine the free-riding problem are Maxwell et al. (2000) and Millock and Salanié (2000). However, in both of these papers the free-rider problem takes the form of "shirking" by all firms, i.e., all firms under-invest in pollution abatement. Neither paper considers equilibria in which a sub-group of firms take voluntary actions, while the remaining firms free-ride. Brau et al. (2000) develop a model in which a sub-group of firms can participate. However, in their model the assumed benefits from participation imply that unless some firms are excluded from participation, under a successful VA no free-riding will occur (i.e., all firms will participate). Thus, their model does not explain the existence of open-membership VAs with less than full participation. The model developed in this paper differs from these previous studies in that it provides an explanation for the existence of free-riding by a subset of firms in equilibrium.

In this paper we develop a multiple-firm model of voluntary adoption of environmental protection measures in which an entire industry is faced with industrywide imposition of a costly government policy, namely, an emissions tax. The policy 
scenario is as follows. A regulator seeks to achieve an exogenous reduction in industrywide emissions. He sets a target emissions cap for the industry as a whole. He then provides the industry with an opportunity to meet the target voluntarily, with the explicit recognition that if the voluntary approach fails to meet the target, an emissions tax will be imposed on the industry, with the magnitude of the tax set at a level sufficient to ensure that the target will be met under the tax. ${ }^{6}$ Because all firms benefit if the target is met but only those firms that reduce their emissions bear costs, firms face a free-rider incentive, i.e., an incentive not to participate and reduce emissions voluntarily. We ask whether it is possible to have a successful voluntary approach despite this free-rider incentive.

Because participation in the voluntary program is voluntary and VAs are not legally binding (Stewart, 1993; Gains and Mfodwo, 1996), in modeling the voluntary approach we assume that it must be in the interest of all firms to adhere to their participation decisions despite the lack of any legal obligation to do so. To formalize this notion, we adopt the concept of a self-enforcing equilibrium that has been applied to the study of stable cartels and international environmental agreements (IEAs) (d'Aspremont, et al., 1983; d'Aspremont and Gabszewicz, 1986; Donsimoni, et al., 1986; Carraro and Siniscalco, 1993; Barrett, 1994). Using the concept of a self-enforcing equilibrium, the model predicts that in equilibrium there will generally be only partial participation in a voluntary program, a result that is consistent with the observations noted above. Nonetheless, the VA is successful in meeting the target, despite the existence (in equilibrium) of free-riders. Thus, the free-rider incentive does not undermine the viability of a voluntary approach. However, it does generate an efficiency loss. This loss 
does not take the usual form of under-provision of the public good. Rather, the voluntary approach yields an inefficient allocation of total pollution abatement across firms. Thus, although there is a cost savings for firms under the voluntary approach, it leads to higher total abatement costs than under imposition of the tax.

The paper is organized as follows. Section 2 presents a simple illustrative example of the participation problem and the implications of free-rider incentives. The remainder of the paper then formalizes the results from the example. In Section 3 we provide an overview of the basic model and the equilibrium under the tax policy. Section 4 defines and characterizes the equilibrium under the voluntary approach using the concept of a self-enforcing equilibrium. In Section 5 we identify the efficiency loss from use of the VA and compare the private returns under the two policies . Section 6 summarizes the main conclusions.

\section{A Simple Illustrative Example}

We begin with a simple illustrative example to motivate our analysis. Consider an industry with only two (identical) firms. Let profits of firm i be given by $\pi\left(e_{i}\right)=100$ $\left(10-e_{i}\right)^{2}$, where $e_{i}$ is the emissions level of firm i. In the absence of any government policy, each firm chooses the profit-maximizing level of $e_{i}$, which is 10 , implying total emissions of 20 units. Suppose now that the regulator wants to reduce total emissions to 16 units. One possibility is to impose an emissions tax of $\$ 4 /$ unit on each firm. This would induce each firm to reduce emissions to 8 units, yielding before-tax profits of $\$ 96$ and after-tax profits of $\$ 64$ per firm. Alternatively, the regulator could offer the firms a chance to meet the aggregate or collective target voluntarily, with an understanding that if 
the target is not met voluntarily, the emissions tax will be imposed. Suppose that if both firms agree to participate in this voluntary approach, they will share the required reduction equally, with each reducing emissions to 8 units. However, if one agrees to participate and the other does not, then the non-participant will continue to emit 10 units, implying that the participant would have to reduce emissions to 6 units in order to ensure that the collective target is met. The resulting payoff matrix is depicted in Figure 1.

Figure 1: Payoff Matrix with a Target of 16 Units

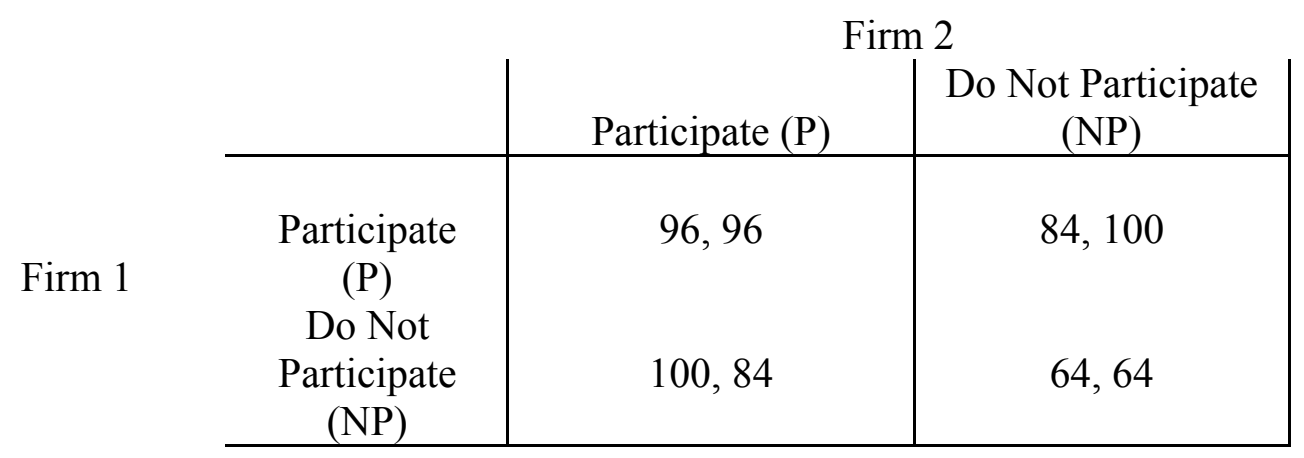

Because of our interest in motivating some of our results using a simple model, here we model the participation decision using the familiar concept of a Nash equilibrium, since in the context of this (and the following) example the Nash equilibria are the selfenforcing equilibria. ${ }^{7}$ The payoff matrix in Figure 1 yields two Nash equilibria in the participation decisions: (P,NP) and (NP,P).

There are several characteristics of these equilibria that should be noted. First, under either equilibria the collective target is met voluntarily. However, both involve "free-riding" in the sense that the target is met entirely through the abatement efforts of one firm. It is not possible to predict which equilibrium will emerge, i.e., which firm will 
participate and which will not. ${ }^{8}$ Nonetheless, it is clear that full participation, i.e., participation by both firms, is not a Nash equilibrium. ${ }^{9}$

Second, the profit level of the non-participant (the free-rider) is higher than the profit level of the participant. Thus, given a choice, a firm would clearly prefer to be in the equilibrium in which it is the non-participant rather than the equilibrium in which it is the participant. Nonetheless, in the equilibrium in which it is the participant, participation is still the best response to the strategy of the other firm. Thus, given that the other firm chooses not to participate, the participant is still better off participating than not. The reason, of course, is that the tax savings realized by avoiding the tax through participation exceeds the additional abatement cost incurred by reducing emissions from 8 to 6 .

Finally, note that each firm's payoff is higher when the target is met voluntarily than when it is not, implying that both the participant and the non-participant strictly prefer to meet the target voluntarily. However, total before-tax profits are lower ( $\$ 184$ in equilibrium vs. $\$ 192$ if the tax is imposed), implying that meeting the target voluntarily results in a welfare loss. The explanation is that, because of free-riding, the required emission reduction is not allocated efficiently across the two firms when the target is met voluntarily, while it is allocated efficiently when the tax is imposed. The outcome that involves no free-riding and maximizes both before- and after-tax aggregate profit, namely $(\mathrm{P}, \mathrm{P})$, is not a Nash equilibrium in the participation decisions.

In the above example, both Nash equilibria implied that the target would be met voluntarily. It is also possible to construct examples where (NP,NP) is also a Nash equilibrium. For example, if the collective target was set at 12 units instead of 16, the 
resulting payoff matrix would be given by Figure 2. With this payoff maxtrix, there are three Nash equilibria: $(\mathrm{P}, \mathrm{NP}),(\mathrm{NP}, \mathrm{P})$ and $(\mathrm{NP}, \mathrm{NP})$. The observations above continue to hold, except that in this case the participant is indifferent between the equilibrium under which the target is met voluntarily and the equilibrium under which the tax is imposed.

Figure 2: Payoff Matrix with a Target of 12 Units

\begin{tabular}{|c|c|c|c|}
\hline & \multicolumn{2}{|c|}{ Firm 2} \\
\hline & & Participate $(\mathrm{P})$ & $\begin{array}{l}\text { Do Not Participate } \\
\text { (NP) }\end{array}$ \\
\hline Firm 1 & $\begin{array}{l}\text { Participate } \\
\text { (P) }\end{array}$ & 84,84 & 36,100 \\
\hline & $\begin{array}{c}\text { Do Not } \\
\text { Participate } \\
\text { (NP) }\end{array}$ & 100,36 & 36,36 \\
\hline
\end{tabular}

The above examples provide some intuition for the results that we derive more generally and more formally below.

\section{An Overview of the Model}

We consider a model in which there are $N$ identical firms. Each firm produces an output level $y_{i}$ and an emission level $e_{i}$. The firm's production costs are given by a continuous function $C\left(y_{i}, e_{i}\right)$, where $C_{y}>0, C_{e} \leq 0, C_{y y} \geq 0, C_{e e} \geq 0$, and $C_{y e} \leq 0$. The cost function is assumed to be the same under both the emission tax policy and the VA, i.e., there is no cost advantage per se from reducing emissions voluntarily. This is in contrast to other models that assume that any given level of emissions reduction can be achieved at a lower cost under the VA than under the alternative policy (typically, a regulation) because the VA gives the firm greater flexibility in choosing its pollution control measures. ${ }^{10}$ It is assumed that firms do not benefit directly from reductions in 
emissions. ${ }^{11}$ Thus, absent any government policy, there is no private incentive for pollution abatement. ${ }^{12}$

As noted above, the regulator seeks to meet an exogenously determined aggregate emissions cap $E$, where $0<E<N e_{0}$ and $e_{0}$ is the equilibrium level of emissions for each firm prior to any government policy. ${ }^{13}$ If in the aggregate the firms meet the emissions cap voluntarily, the regulator will not impose a tax on the industry. However, if the firms fail to meet the cap collectively, the regulator will impose a uniform emission tax $t$ on the entire industry, with the magnitude of the tax set at the level necessary to ensure that the emissions cap $E$ is met. ${ }^{14}$

Because the incentive to participate in the voluntary initiative depends on the payoffs that firms can expect to realize if the tax is imposed, we consider first the equilibrium under a tax. We view this as a 3-stage game. In Stage 1, the government agency or regulator sets the emissions tax rate. In Stage 2, each firm chooses its emissions level, taking the emissions levels of all other firms as given. In Stage 3, the firms engage in Cournot competition in the output market, facing an aggregate demand curve of $P(Y),{ }^{15}$ where $Y=\sum_{1}^{N} y_{i}$.

In a symmetric Nash equilibrium, Stage 3 Cournot competition yields profitmaximizing output levels $y_{i}^{t}=y^{t}(e)$ that are the same for all firms and depend on the (common) emissions level chosen in Stage 2. ${ }^{16}$ Substituting these into each firm's profit function gives before-tax profits as a function of $e$, i.e., $\pi(e) \equiv P\left(Y^{t}(e)\right) y^{t}(e)-C\left(y^{t}(e), e\right)$, where $Y^{t}(e)=N y^{t}(e)$. In Stage 2, each firm chooses its emissions level to maximize aftertax profits $\pi(e)$-te, given the emissions levels of all other firms. This yields an optimal emissions level $e^{*}(t)$, which depends on the tax rate $t .{ }^{17}$ In Stage 1 , the regulator sets the 
tax rate to ensure that the target will be met. The resulting tax rate $t^{*}$ is implicitly defined by $N e^{*}\left(t^{*}\right)=E$. Note that $t^{*}$ is homogeneous of degree zero in $(N, E)$. Thus, the emissions tax depends only on the stringency of the emissions cap $(E / N)$. If faced with this tax, each firm will earn an after-tax profit level of $\left.\pi_{t}^{*} \equiv \pi\left(e^{*}\left(t^{*}\right)\right)-t^{*} e^{*}\left(t^{*}\right)\right)$.

\section{Equilibrium under the VA}

We turn next to the equilibrium under the voluntary approach. Again, we view the problem as a 3-stage game. In Stage 1, each firm decides whether or not to join the group of firms that participate in the voluntary approach, where participation entails a commitment to share equally with all other participants the emission reductions that are necessary to ensure that the collective target is met. If no firms choose to participate, the VA fails and the firms play the tax game described in the previous section. ${ }^{18}$ If a nonempty subset of firms chooses to participate, the game proceeds to Stage 2. In Stage 2, each non-participant chooses its emissions level to maximize profits, given the emissions levels of all other non-participating firms and the commitment of participating firms. In Stage 3, all firms engage in Cournot competition in the output market. We model the Stage 2 and Stage 3 decisions as Nash equilibria. ${ }^{19}$ For simplicity, we consider only symmetric equilibria in Stages 2 and 3, i.e., equilibria in which all participating firms choose the same emissions and output levels ${ }^{20}$ and all non-participating firms do as well. In contrast, because Stage 1 decisions involve commitment to join a group, we model the Stage 1 equilibrium using the concept of a self-enforcing equilibrium.

Let $N_{p}$ denote the number of firms that choose to participate in Stage 1, and let $N_{n}=N-N_{p}$ be the number of non-participating firms. We solve the game through backward 
induction and hence consider the Stage 3 equilibrium first. Let $e_{p}$ denote the (common) emissions level of a participating firm, and let $e_{n}$ denote the corresponding level for a non-participating firm. In Stage 3, both types of firms choose their output levels to maximize their own profits, given these emissions levels. More specifically, participating firms choose the output level $y_{p}$ that maximizes ${ }^{21}$

$$
P\left(y_{p}+\left(N_{p}-1\right) \bar{y}_{p}+\left(N-N_{p}\right) \bar{y}_{n}\right) y_{p}-C\left(y_{p}, e_{p}\right),
$$

while non-participating firms choose the output level $y_{n}$ that maximizes

$$
P\left(N_{p} \bar{y}_{p}+\left(N-N_{p}-1\right) \bar{y}_{n}+y_{n}\right) y_{n}-C\left(y_{n}, e_{n}\right) .
$$

The corresponding Nash equilibrium yields output levels $y_{p}{ }^{*}\left(e_{p}, e_{n}, N_{p}\right)$ and $y_{n}{ }^{*}\left(e_{p}, e_{n}, N_{p}\right)$. The corresponding profit levels are

$$
\begin{aligned}
& P\left(Y^{*}\left(e_{p}, e_{n}, N_{p}\right)\right) y_{p}{ }^{*}\left(e_{p}, e_{n}, N_{p}\right)-C\left(y_{p}{ }^{*}\left(e_{p}, e_{n}, N_{p}\right), e_{p}\right) \quad \text { and } \\
& P\left(Y^{*}\left(e_{p}, e_{n}, N_{p}\right)\right) y_{n}{ }^{*}\left(e_{p}, e_{n}, N_{p}\right)-C\left(y_{n}{ }^{*}\left(e_{p}, e_{n}, N_{p}\right), e_{n}\right),
\end{aligned}
$$

respectively, where $Y^{*}\left(e_{p}, e_{n}, N_{p}\right)=N_{p} y_{p}{ }^{*}\left(e_{p}, e_{n}, N_{p}\right)+\left(N-N_{p}\right) y_{n}{ }^{*}\left(e_{p}, e_{n}, N_{p}\right)$.

Given the optimal output choices and resulting profits levels from Stage 3, we now consider the equilibrium in Stage 2. A Stage 2 equilibrium is defined by two conditions. The first is that each non-participating firm chooses its emissions level to maximize its profits in (4), given the emissions levels of all other firms. ${ }^{22}$ The second condition requires that the emissions level for each participating firm be the level that ensures that the target is met, given the emissions levels of the non-participating firms, i.e., ${ }^{23}$

$$
e_{p}=\left\{E-\left(N-N_{p}\right) e_{n}\right\} / N_{p} \text {. }
$$

These two conditions combined determine the equilibrium emissions levels $e_{p}{ }^{*}\left(N_{p}\right)$ and $e_{n}{ }^{*}\left(N_{p}\right)$ as functions of the number of participating firms. Substituting these into (3) and 
(4) gives the maximized level of profits for participants and non-participants, $\pi_{p}{ }^{*}\left(N_{p}\right)$ and $\pi_{n}^{*}\left(N_{p}\right)$, as functions of the number of participating firms.

Note that an increase in $N_{p}$ can affect the profits of both participating and nonparticipating firms in two ways: (1) through the impact on emissions (a direct effect), and (2) through the impact on output choices (an indirect effect). To see the direct effect, first note that if the cost function is strongly separable, i.e., if $C_{y e}=0$, then the Stage 3 equilibrium, i.e., the optimal output choice, is independent of the emissions levels. This implies that both participating and non-participating firms will choose the same output levels, which in turn implies that both those output levels and the corresponding price will be independent of the number of participating firms. Thus, the effect of $N_{p}$ on profits is just the direct effect that occurs through the choice of emissions level. For nonparticipating firms, the emissions level that would be chosen under separability is determined by the first-order condition

$$
-C_{e}=0
$$

which is independent of $N_{p}$. Thus, under separability, $\partial \pi_{n}^{*} / \partial N_{p}=0$, i.e., the direct effect is zero. For participating firms, the level of emissions is determined by (5). This implies that

$$
\partial \pi_{p}^{*} / \partial N_{p}=C_{e}\left(E-N e_{n}\right) / N_{p}^{2}>0 .
$$

Thus, as expected, an increase in the number of participating firms directly increases the profits of each participating firm, since the emissions reduction that each participant must undertake to ensure the target is met is reduced when the number of participants increases. 
When the cost function is not strongly separable, a second, indirect effect exists as well. In this case, the firms' optimal output choices depend on emissions levels since emissions levels affect marginal production costs. Hence, output choices will be different for participating and non-participating firms, implying that the total output (and hence price) in the market will depend on the number of participating firms. This price effect then further affects equilibrium output levels and thus profits. While these indirect effects through the output market can exist, the existing empirical evidence suggests that even for heavily polluting industries emission abatement costs constitute a relatively small share of production costs (see, for example, Jaffe et al., 1995). For this reason, we assume throughout the remainder of the paper that these effects are "small", and hence that the total effects of a change in the number of participating firms are dominated by the direct effects described above. Thus, in what follows we assume that an increase in the number of participating firms increases profits for participating firms but has no significant effect on the profits of non-participants. Note that this implies that $\pi_{n}{ }^{*}\left(N_{p}\right) \equiv \pi_{n}{ }^{*}>\pi_{p}{ }^{*}\left(N_{p}\right)$ for all $N_{p}<N$. This simply says that when the target is met at any participation rate less than full participation, non-participants earn a higher profit than participants.

We are now in a position to identify the Stage 1 equilibria that are self-enforcing, i.e., both profitable and stable (both externally and internally) in the sense defined in the literature on international environmental agreements and stable cartels ((d'Aspremont, et al., 1983; d'Aspremont and Gabszewicz, 1986; Donsimoni, et al., 1986; Carraro and Siniscalco, 1993; Barrett, 1994). The need for self-enforcement stems from the fact that participation in the voluntary approach is not binding, and hence there is no binding 
commitment on the part of the participants. Instead, in equilibrium the participation decisions of all firms and the resulting number of participating firms should be such that continued participation in the group is in the self-interest of participating firms, and no non-participants want to join. This requires that the equilibrium be both profitable and internally and externally stable.

Following Carraro and Siniscalco (1993) and Barrett (1994), an equilibrium $\left(N_{p}\right)$ is profitable if $\pi_{p}{ }^{*}\left(N_{p}\right) \geq \pi_{t}{ }^{*}$, i.e., if at this equilibrium the participating firms are at least as well off under the voluntary program as they would have been without the program (and hence with the tax). ${ }^{24}$ Furthermore, an equilibrium is both internally and externally stable if (i) no participating firm has an incentive to defect unilaterally, i.e., to become a non-participating firm; and (ii) no non-participating firm has an incentive to join unilaterally, i.e., to become a participating firm. ${ }^{25}$

To identify equilibria that are stable and hence self-enforcing, we must define more explicitly the payoffs from participation (and hence from accession and defection) at various levels of participation. To do this, we first define $N_{p}{ }^{*}$ to be the minimum number of participating firms necessary to make the voluntary approach profitable for the participating firms. Thus, if $\pi_{p}{ }^{*}(1)<\pi_{t}{ }^{*}$, then $N_{p}{ }^{*}$ is the level of $N_{p}$ such that

$$
\pi_{p}^{*}\left(N_{p}^{*}\right) \geq \pi_{t}^{*} \text { but } \pi_{p}^{*}\left(N_{p}^{*}-1\right)<\pi_{t}^{*}
$$

(See Figure 3.) Alternatively, if $\pi_{p}{ }^{*}(1) \geq \pi_{t}{ }^{*}$, i.e., if it is profitable for one firm to meet the target on its own, then $N_{p}{ }^{*}=1$. Clearly, any value of $N_{p}<N_{p}{ }^{*}$ implies that the coalition is not profitable. In addition, given $\partial \pi_{p}{ }^{*} / \partial N_{p}{ }^{*}>0$, if a coalition is profitable at $N_{p}{ }^{*}$, it is profitable for any higher level of participation. Thus, the only possible self-enforcing equilibria are equilibria with $N_{p} \geq N_{p}^{*}$. 
Because of the importance of $N_{p}{ }^{*}$ in identifying and characterizing the selfenforcing equilibria, before proceeding we establish the existence of a minimum profitable participation level.

Proposition 1: A unique minimum profitable participation level $N_{p}{ }^{*}$ always exists, where $1 \leq N_{p}^{*} \leq N$

Proof: If $\pi_{p}{ }^{*}(1) \geq \pi_{t}{ }^{*}$, then by definition $N_{p}{ }^{*}$ exists and is equal to one. Suppose instead that $\pi_{p}{ }^{*}(1)<\pi_{t}{ }^{*}$. In addition, note that $\pi_{p}{ }^{*}(N)=\pi(E / N)>\pi_{t}{ }^{*}$. This, coupled with the continuity and monotonicity of $\pi_{p}{ }^{*}\left(N_{p}\right)$, ensures the existence of a unique value of $1<n \leq N$ at which $\pi_{p}{ }^{*}(n)=\pi_{t}{ }^{*} . \mathrm{N}_{\mathrm{p}}{ }^{*}$ is then simply the largest integer greater than or equal to $n$.

\section{$Q E D$}

To determine which of the profitable equilibria are stable, we note that a level of participation that is not profitable will lead to a dissolution of the coalition and hence the imposition of the tax. Conversely, a level of participation that is profitable will yield the payoffs described above, which were conditional on the collective target being met voluntarily, i.e., on the coalition being profitable. Thus, the unconditional payoffs for participants and non-participants are given by:

and

$$
\pi_{p}\left(N_{p}\right)= \begin{cases}\pi_{t}{ }^{*} & \text { if } N_{p}<N_{p}{ }^{*} \\ \pi_{p}{ }^{*}\left(N_{p}\right) & \text { if } N_{p} \geq N_{p}{ }^{*}\end{cases}
$$

$$
\pi_{n}\left(N_{p}\right)=\left\{\begin{array}{lll}
\pi_{t}{ }^{*} & \text { if } & N_{p}<N_{p}{ }^{*} \\
\pi_{n}{ }^{*} & \text { if } & N_{p} \geq N_{p}{ }^{*}
\end{array}\right.
$$


Note that at $N_{p}=N, \pi_{p}\left(N_{p}\right)$ is equal to the profit level that would be realized if all firms participated and hence shared equally in the allowable emissions, $\pi(E / N)$. This profit level is less than $\pi_{t}^{*}$ by the amount of the tax payment, $t^{*} E / N$. The two profit functions are depicted in Figure 4.

These two profit functions can now be used to define external and internal stability:

Definition: An equilibrium with $N_{p}$ firms participating is internally and externally stable if and only if

(i) $\pi_{p}\left(N_{p}\right) \geq \pi_{n}\left(N_{p^{-}}-1\right) \quad$ (no firm has an incentive to defect), and

(ii) $\pi_{n}\left(N_{p}\right) \geq \pi_{p}\left(N_{p}+1\right) \quad$ (no firm has an incentive to accede).

Using the definition of stability and the above profit functions, we can establish the following:

Proposition 2: A coalition of $N_{p}$ participating firms is a self-enforcing equilibrium under which the target is met voluntarily if and only if $N_{p}=N_{p}{ }^{*}$.

Proof: The "if" part of the proposition is easily verified using the profit functions above. For the "only if" part, we need to consider only values of $N_{p}$ for which $N_{p}>N_{p} *$ (since any outcome with $N_{p}<N_{p} *$ is by definition not profitable and hence cannot be a self-enforcing equilibrium). However, for any integer $N_{p}>N_{p}{ }^{*}, N_{p}-1 \geq N_{p}{ }^{*}$. Thus, $\pi_{n}\left(N_{p^{-}}-1\right)=\pi_{n}{ }^{*}>\pi_{p}\left(N_{p}\right)=\pi_{p}{ }^{*}\left(N_{p}\right)$, which violates $(i)$. Thus, any equilibrium with $N_{p}>N_{p}{ }^{*}$ cannot be self-enforcing. $\boldsymbol{Q E D}$ 
Proposition 2 implies that the only self-enforcing equilibrium is the equilibrium with the minimum amount of profitable participation. Thus, as long as $N_{p}{ }^{*}<N$, a full participation equilibrium will not be self-enforcing. Some amount of free-riding is expected to occur under a successful voluntary approach because of the tax savings generated by the voluntary program. ${ }^{26}$ Note that because of the cost savings that result from avoiding an emissions tax, participating firms are willing to reduce their emissions to a level below what they would have chosen under the tax $(E / N)$.

At the self-enforcing equilibrium the profit level is higher for non-participating firms than for participating firms. Thus, if a participating firm could exchange places with a non-participating firm, i.e., become a non-participant without affecting the number of participating firms, it would always have an incentive to do so. However, the conditions for stability ensure that in a self-enforcing equilibrium a participating firm has no incentive to defect unilaterally, despite the fact that it realizes lower profits than the non-participating firms. The reason, of course, is that at the self-enforcing equilibrium the coalition would fall apart if one firm unilaterally defected (since it would no longer be profitable), which would trigger imposition of the tax and thereby yield a profit level for the would-be defector that was no higher than it would have realized if it had continued to participate in the voluntary approach.

We turn next to a key result that establishes the viability of the voluntary approach.

Proposition 3: A self-enforcing equilibrium under which the target is met voluntarily always exists. 
Proof: This follows directly from Propositions 1 and 2. $Q E D$

The intuition behind Proposition 3 is as follows. It is clear that a coalition with full participation is always profitable since each firm incurs the same abatement cost as it would have incurred under the tax but avoids the tax payment. If defection by a single firm would yield a coalition size that is not profitable, then the full coalition is selfenforcing. If a coalition of size $N-1$ is still profitable, then the full coalition is not stable, but the coalition of size $N-1$ is a possible self-enforcing equilibrium (if it is stable). By iteratively moving backward starting from the full coalition, we can identify the coalition size where any further defections would yield a remaining coalition that is not profitable. This coalition is then stable and profitable, and hence self-enforcing. If the coalition of one (i.e., $N_{p}=1$ ) is not profitable, then this iterative process will stop at a coalition size greater than or equal to two, under which the target would be met voluntarily. Conversely, if the coalition of one is profitable, this iterative process will stop at the coalition of one, since under this condition this coalition is also stable (i.e., the single participant cannot do better by defecting). Thus, in either case, the iterative process will stop at a coalition of strictly positive size, implying the existence of a self-enforcing equilibrium under which the target is met voluntarily. Note that this implies that, even if a voluntary program is not feasible for a low $N_{p},{ }^{27}$ there always exists a value of $N_{p} \geq 1$ (namely, $N_{p}{ }^{*}$ ) at which the target can be met voluntarily, and in a manner that is profitable in the sense defined above. 
While the minimum participation equilibrium is the only self-enforcing equilibrium under which the target is met, it is also possible to have a self-enforcing equilibrium under which the target is not met.

Proposition 4: $N_{p}=0$ is a self-enforcing equilibrium under which the target is not met voluntarily if and only if $\pi_{p}{ }^{*}(1) \leq \pi_{t}{ }^{* 28}$

Proof: Since there are no participating firms, profitability holds trivially. In addition, if $\pi_{p}^{*}(1) \leq \pi_{t}^{*}$, then at $N_{p}=0, \pi_{n}\left(N_{p}\right)=\pi_{t}^{*} \geq \pi_{p}^{*}\left(N_{p}+1\right)$, which implies that no firm has an incentive to accede to form a coalition of one. Conversely, if $\pi_{p}{ }^{*}(1)>\pi_{t}{ }^{*}$, then $\pi_{n}\left(N_{p}\right)=\pi_{t}^{*}<\pi_{p}^{*}\left(N_{p}+1\right)$, which implies that $N_{p}=0$ is not stable and hence not selfenforcing. $\boldsymbol{Q E D}$

Note, however, that even if the zero participation outcome is self-enforcing, a self-enforcing equilibrium with positive participation $\left(N_{p}^{*}\right)$ also exists (by Proposition 3 ). In addition, each firm in the industry is at least as well off and some are strictly better off at the equilibrium under which the target is met voluntarily than at the equilibrium under which it is not. In this sense, the equilibrium under which the target is met voluntarily pareto dominates. Thus, even when multiple self-enforcing equilibria exist, we might expect firms to choose the (unique) equilibrium under which it is met voluntarily.

\section{Policy Comparisons}

The results in the previous section imply that, unless $N_{p}{ }^{*}=N$, some amount of free-riding will result under a successful voluntary approach, because of the tax savings 
that can be realized if the emissions cap is met voluntarily. Note, however, that because the cap is met under either the tax policy or the voluntary program, free-riding does not lead to under-provision of the public good (environmental quality). It does, however, affect both the total private and social costs of supplying that level of the public good.

Proposition 5: Aggregate profit for the industry is higher when the target is met voluntarily than under the emissions tax.

Proof: The industry-wide aggregate profits under the tax policy are given by $\Pi_{t}=N \pi_{t}^{*}$. Aggregate profits when the target is met voluntarily are $\Pi_{V}=\left(N-N_{p}^{*}\right) \pi_{n}^{*}+N_{p}^{*} \pi_{p}^{*}\left(N_{p}^{*}\right)$. Thus,

$$
\Pi_{V}-\Pi_{t}=\left(N-N_{p}^{*}\right)\left(\pi_{n}^{*}-\pi_{t}^{*}\right)+N_{p}^{*}\left(\pi_{p}^{*}\left(N_{p}^{*}\right)-\pi_{t}^{*}\right)>0
$$

where the inequality follows from $\pi_{n}{ }^{*}>\pi_{t}{ }^{*}$ and $\pi_{p}{ }^{*}\left(N_{p}{ }^{*}\right) \geq \pi_{t}{ }^{*}$. $Q \boldsymbol{E} \boldsymbol{D}$

Thus, as expected, aggregate profits are higher when the target is met voluntarily than when it is met through imposition of the tax, since at a self-enforcing equilibrium all firms are at least as well off under the voluntary program as they are under the tax. Interestingly, however, in equilibrium the aggregate profit gain that results from the use of the voluntary program is not the aggregate tax savings $\left(t^{*} E\right)$. The profit differential for the non-participants exceeds the magnitude of their tax savings (which is $t^{*} E / N$ per firm). It reflects the gain both from not having to pay any tax on emissions and from not having to undertake any abatement under the voluntary approach. In contrast, when $N_{p}{ }^{*}<N$, the profit gain to participants is less than the magnitude of their tax savings, since they undertake more abatement under the voluntary program than they would have undertaken under the tax. ${ }^{29}$ 
Given the result in Proposition 5, we would expect the industry as a whole to prefer the voluntary program since all firms are individually at least as well off and collectively better off than under the tax. However, as stated below, use of the voluntary approach will actually lead to higher social costs than would have resulted under the tax policy. ${ }^{30}$

Proposition 6: If $N_{p}{ }^{*}<N$, the total social cost of meeting the emissions cap $E$ is higher when the target is met voluntarily than under the tax policy.

This follows directly from the fact that, when firms are identical and the profit function is strictly concave, ${ }^{31}$ the total cost of meeting the cap is minimized when emissions are distributed equally across all firms (Baumol and Oates, 1988). This occurs under the tax policy (all firms emit $\left.e_{t}{ }^{*}\left(t^{*}\right)\right)$ but not under the voluntary approach (since in equilibrium participants emit less than non-participants). Thus, despite the fact that no firm is any worse off under the voluntary program and each participating firm has full flexibility to meet its own emission level in a cost-minimizing way, there is a social cost associated with using a voluntary program rather than a tax to meet the aggregate emissions cap because of the unequal (and hence inefficient) distribution of abatement across firms. ${ }^{32}$

The increased social costs associated with the voluntary approach stem from the threatened imposition of an emissions tax, which is costly to firms. If the regulator could credibly threaten imposition of a first-best regulation, ${ }^{33}$ under which each firm would realize a profit of $\pi(E / N)$, the results would be different. In this case, the only selfenforcing equilibrium under which the target is met is the full-participation equilibrium. 
With full participation, the allocation of abatement is efficient across all firms and thus total social costs are the same under the regulation as under the voluntary approach. However, under a first-best regulation there is also no gain to the industry from the voluntary approach. ${ }^{34}$ Hence, there is no reason for either the industry or the regulator to want to use the voluntary approach.

\section{Summary and Conclusions}

There is an increased interest in the use of voluntary approaches to environmental protection as an alternative to more traditional regulatory approaches. In many cases, entire industries are faced with possible imposition of costly environmental policies if environmental goals are not met voluntarily. If the threat is industry-wide, a potential free-rider problem exists since, if the environmental goal is met by others, individual firms would benefit from avoidance of the costly policy without incurring the associated cost.

In this paper, we developed a multiple-firm model in which an industry is faced with an aggregate emissions limit and given an opportunity to meet the target voluntarily, with the explicit recognition that failure to do so would result in imposition of an industry-wide emissions tax. Faced with this prospect, we ask whether a voluntary approach can be successful, given the incentive for individual firms to free ride. We show that a self-enforcing equilibrium under which the target is met voluntarily always exists, and occurs at the minimum profitable participation level. Thus, the only selfenforcing equilibrium under which the target is met voluntarily will involve free-riding (unless free riding by just one firm makes the coalition unprofitable). The zero 
participation outcome (under which the target is not met voluntarily) can also be a selfenforcing equilibrium. However, it is pareto dominated by the equilibrium under which the target is met voluntarily. Thus, even though free-riding is a likely outcome in equilibrium (i.e., a self-enforcing equilibrium will not generally involve full participation), the free-rider incentive does not destroy the viability of successfully using an industry-wide voluntary approach.

As expected, free-riding generates an efficiency loss. However, this loss does not take the usual form of under-provision of the public good. Rather, it takes the form of an increase in the cost of providing the (fixed) level of the public good. An emissions tax ensures that the aggregate emissions target is met at least cost. With identical firms, this results when emissions reductions are allocated uniformly across firms. Under the voluntary approach, the allocation of emissions reductions is no longer uniform, since participating firms reduce emissions by more than than non-participants. This unequal distribution of abatement across firms results in a higher overall cost of meeting the aggregate emission reduction goal. Thus, despite the fact that firms have full flexibility to meet their emissions reductions in the least cost way, total social costs are higher under the voluntary approach.

Although the voluntary approach results in higher social costs, it generates a gain for both participating and non-participating firms, and hence for the industry as a whole. This gain stems from the avoided tax payments. However, the magnitude of that gain is not given by the amount of the avoided tax payments. Non-participants gain more than their avoided tax payments, while participants gain less. Nonetheless, all firms are at least as well off and at least some are always strictly better off than under the tax 
alternative, which suggests that the industry would prefer and hence lobby for the voluntary approach. ${ }^{35}$

Would a regulator ever prefer the voluntary approach? Within the context of the model developed here, the regulator would never prefer the voluntary approach to the tax, because of the increase in the total cost of meeting the target. ${ }^{36}$ However, the model abstracts from a number of potential benefits from using a voluntary approach (such as increased cooperation and reduced political resistance - see, for example, CEC (1996)) as well as potential imperfections in the design of an emissions tax (such as an inability to tax all emissions - see, for example, Nyborg (2000)). Because these aspects of voluntary approaches and taxes are not included here, we draw no overall conclusions about the relative welfare effects of the two policy approaches. Nonetheless, we have shown that, while an industry-wide voluntary approach can be successful despite the free-rider problem, the free-rider problem does create an efficiency loss, not through underprovision of the public good but rather through an increase in the cost of providing it. 


\section{References}

Arora, S. and S. Gangopadhyay (1995), "Toward A Theoretical Model of Voluntary Overcompliance," Journal of Economic Behavior and Organization, 28(3): 289-309.

Aggeri, F. and A. Hatchuel (1999), "A Dynamic Model of Environmental Policies," in C. Carraro and F. Lévêque (eds.) Voluntary Approaches in Environmental Policy, Dordrecht: Kluwer Academic Publishers, pp. 151-85.

Bagnoli, Mark and Barton L. Lipman (1989), "Provision of Public Goods: Fully Implementing the Core through Private Contributions," Review of Economic Studies, 56: 583-601.

Bagnoli, Mark and Michael McKee (1991), "Voluntary Contribution Games: Efficient Private Provision of Public Goods," Economic Inquiry, 29: 351-366.

Barrett, Scott (1994), "Self-enforcing International Environmental Agreements," Oxford Economic Papers, 46(5), Supplement, October: 878-94.

Baumol, W. J. and W.E. Oates (1988), The Theory of Environmental Policy, Cambridge: Cambridge University Press.

Becker, N. and K.W. Easter (1999), "Conflict and Cooperation in Managing International Water Resources Such as the Great Lakes," Land Economics, 75(2): 233-45.

Botteon, M. and C. Carraro (1997), "Burden-Sharing and Coalition Stability in Environmental Negotiations with Asymmetric Countries," in C. Carraro. (ed.) International Environmental Agreements: Strategic Policy Issues, Cheltenham and Brookfield: Edward Elgar Publishing, pp. 26-55.

Brau, R., C. Carraro and G. Golfetto (2000), "Endogenous VAs, Coalition Formation and Market Structure," paper presented at the CAVA workshop on "Voluntary Approaches, Competition and Competitiveness", May 25-26 $6^{\text {th }}$, 2000, Milan, Italy.

Carraro, C. and F. Lévêque (1999), "Introduction: The Rationale and Potential of Voluntary Approaches," in C. Carraro and F. Lévêque, (eds.) Voluntary Approaches In Environmental Policy, Dordrecht: Kluwer Academic Publishers, pp. 1-15.

Carraro, C. and D. Siniscalco (1993), "Strategies for the International Protection of the Environment," Journal of Public Economics, 52: 309-328.

Cavaliere, A. (1998), "Voluntary Agreements, Overcompliance and Environmental Reputation," paper presented at World Congress of Environmental and Resource Economists, June 1998, Venice, Italy. 
Chidiak, M. (1999), "Choosing a Tax, a Voluntary Agreement or a Policy-Mix: A Model Based on the Danish $\mathrm{CO}_{2}$ Scheme," paper presented at CAVA workshop on "The Efficiency of Voluntary Approaches in Environmental Policy - What Can be Derived From Theory?”, May 25-26 th, 1999, Copenhagen, Denmark.

Commision of the European Communities (CEC) (1996), On Environmental Agreements, Communication from the Commission to the Council and the European Parliament, Brussels.

d'Aspremont, C.A., A. Jacquemin, J.J. Gabszewicz and J.A. Weymark (1983), "On the Stability of Collusive Price Leadership," Canadian Journal of Economics, 16(1): $17-25$.

d'Aspremont, C.A. and J.J. Gabszewicz (1986), "On the Stability of Collusion,” in J.E. Stiglitz and G.F. Matthewson (eds.) New Developments in the Analysis of Market Structure, Cambridge, Massachusetts: MIT Press, pp. 243-61.

Davis, T. and J. Mazurek (1996), Industry Incentives for Environmental Improvement: Evaluation of US Federal Initiatives, prepared for Global Environmental Management Initiative, Resources for the Future, Washington D.C.

Donsimoni, M.P., N.S. Economides and H.M. Polemarchakis (1986), "Stable Cartels," International Economic Review, 27(2): 317-27.

European Environmental Agency (EEA) (1997), Environmental Agreements: Environmental Effectiveness, Environmental Issue Series No. 3, vol. 1-2, Copenhagen.

Esty, D. C. (1997), "Clean and Competitive: Business-Led Enviromental Management," In S. S. Batie, D.E. Ervin, and M.A. Schultz, (eds.) Business-led Initiatives in Environmental Management: The Next Generation of Policy?, Special Report 92, Proceedings of Pre-conference Workshop to the American Agricultural Economics Association Annual Meeting, Toronto, pp. 37-58.

Gains, S.F. and K. Mfodwo (1996), "Voluntary Agreements in Environmental Regulation with Particular Reference to New Zealand (Voluntary Agreements I)," The Australian Journal of Natural Resources Law and Policy, 3(2): 271-338.

Goodin, R.E. (1986), "The Principle of Voluntary Agreement," Public Administration, 64: 435-44.

Jaffe, A., S.R. Peterson, P.R. Portney, and R.N. Stavins (1995), "Environmental Regulation and the Competitiveness of U.S. Manufacturing: What Does the Evidence Tell Us?" Journal of Economic Literature, 33: 132-163. 
Jochem, E. and W. Eichhammer (1999), "Voluntary Agreements as an Instrument To Substitute Regulations and Economic Instruments: Lessons from the German Voluntary Agreements on $\mathrm{CO}_{2}$ Reduction," in C. Carraro and F. Lévêque, (eds.), Voluntary Approaches in Environmental Policy, Dordrecht: Kluwer Academic Publishers, pp. 209-227.

Khanna, M. (2001), "Economic Analysis of Non-Mandatory Approaches to Environmental Protection," Journal of Economic Surveys, 15 (3): 291-324.

Khanna, M. and L. Damon (1999), "EPA's Voluntary 33/50 Program: Impact on Toxic Releases and Economic Performance of Firms," Journal of Environmental Economics and Management, 37(1): 1-25.

Lévêque, F. and A. Nadaï (1995), "A Firm's Involvement in the Policy-Making Process," in H. Folmer, H.L. Gabel and H. Opschoor (eds.) Principles of Environmental and Resource Economics, Cheltenham and Lyme: Edward Elgar, pp. 299-327.

Marks, Melanie B. and Rachel T.A. Croson (1999), "The Effect of Incomplete Information in a Threshold Public Goods Experiment," Public Choice, 99: $103-118$.

Maxwell, J., T. Lyon, and S.C. Hackett (2000), "Self-Regulation and Social Welfare: The Political Economy of Corporate Environmentalism," Journal of Law and Economics, 43(2), October: 583-618.

Millock, K. (1999), "The Combined Use of Taxation and Voluntary Agreements for Energy Policy," paper presented at CAVA workshop on "The Efficiency of Voluntary Approaches in Environmental Policy - What Can be Derived From Theory?" May 25-26 ${ }^{\text {th }}$, 1999, Copenhagen, Denmark.

Millock, K. and F. Salanié (2000), “Are Collective Environmental Agreements Ever Effective?" working paper, EIRED and LEERNA.

Nyborg, K (2000), "Voluntary Agreements and Non-Verifiable Emissions," Environmental and Resource Economics, 17: 125-144.

Organisation for Economic Co-operation and Development (OECD) (1999), Voluntary Approaches for Environmental Policy: An Assessment, Paris.

Rondeau, Daniel, William D. Schulze, and Gregory L. Poe (1999), "Voluntary Revelation of the Demand for Public Goods Using a Provision Point Mechanism," Journal of Public Economics, 72: 455-470.

Segerson, K. and N.L. Dawson (2001), "Environmental Voluntary Agreements: Participation and Free Riding," in Eric Orts and Kurt Deketelaere, (eds.) Environmental Contracts: Comparative Approaches to Regulatory Innovation in 
Europe and the United States, Dordrecht: Kluwer Law International, pp. 369-388.

Segerson, K. and N. Li (1999), "Voluntary Approaches to Environmental Protection," in H. Folmer, and T. Tietenberg, (eds.) The International Yearbook of Environmental and Resource Economics 1999/2000, Cheltenham, UK: Edward Elgar, pp. 273-306.

Segerson, K. and T.J. Miceli (1998), "Voluntary Environmental Agreements: Good or Bad News for Environmental Quality?" Journal of Environmental Economics and Management, 36(2): 109-30.

Segerson, K. and T.J. Miceli (1999), "Voluntary Approaches to Environmental Protection: The Role of Legislative Threats," in C. Carraro and F. Lévêque (eds.) Voluntary Approaches in Environmental Policy, Dordrecht, Boston and London: Kluwer Academic Publishers, pp. 105-20.

Smart, B. (eds.) (1992), Beyond compliance: A New Industry View of the Environment, Washington DC: World Resource Institute.

Stewart, R.B. (1993), "Environmental Contracts and Covenants: a United States Perspective," in J.M. van Dunné (ed.) Environmental Contracts and Covenants: New Instruments for a Realistic Environmental Policy? Proceedings of an International Conference held in Rotterdam, October 14-16, 1992, pp. 159-81.

Stranlund, J.K. (1995), "Public Mechanisms to Support Compliance to an Environmental Norm," Journal of Environmental Economics and Management, 28(2): 205-222.

Wu, J. and B.A. Babcock (1995), "Optimal Design of a Voluntary Green Payment Program Under Asymmetric Information," Journal of Environmental Economics and Management, 20(2): 316-27.

Wu, J. and B.A. Babcock (1996), "Contract Design for the Purchase of Environmental Goods from Agriculture," American Journal of Agricultural Economics, 78(4): 935-45. 
Figure 3: $\quad$ Minimum Participation Level when $\pi_{p}{ }^{*}(1)<\pi_{t}{ }^{*}$

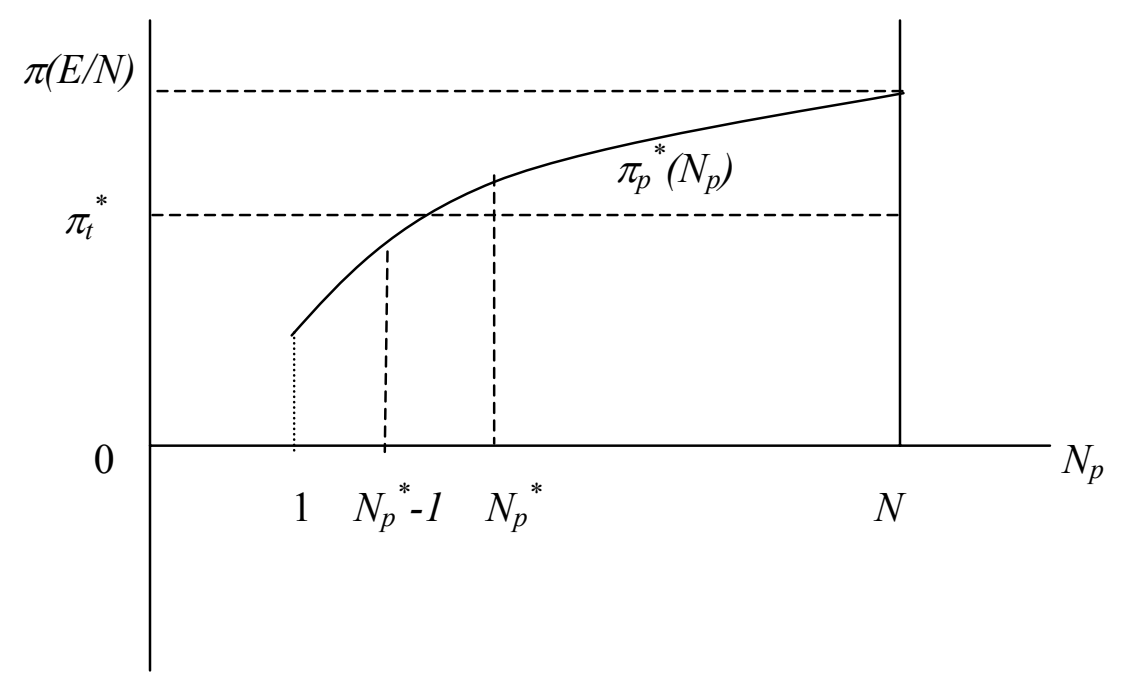

Figure 4: Unconditional Profit Function of Participating and Non-Participating Firms

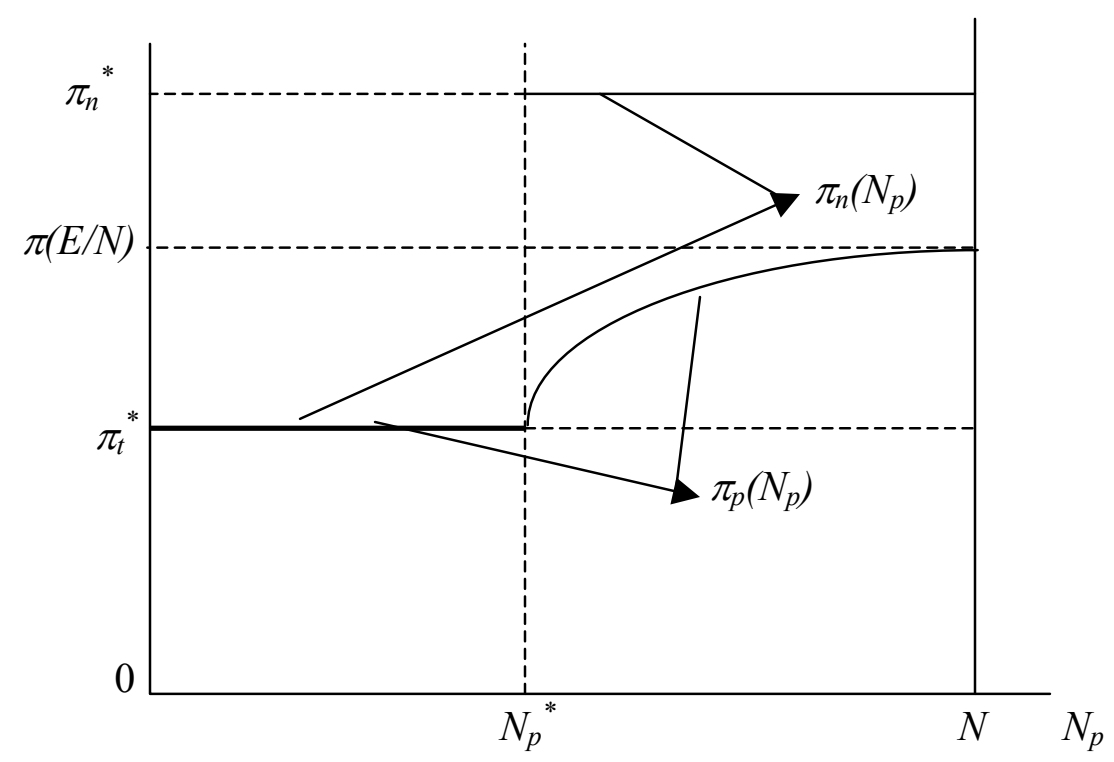




\section{Endnotes}

\footnotetext{
${ }^{1}$ We acknowledge the helpful comments from the participants at the CAVA workshop on "Voluntary Approaches, Competition and Competitiveness" and the University of Pennsylvania/Wharton Impact Conference on "Environmental Contracts", as well as seminar participants at Columbia University, Clark University, and the University of Connecticut. In addition, this paper has benefited greatly from the comments on two anonymous reviewers.
}

${ }^{2}$ Voluntary approaches to environmental protection can take three forms: (i) unilateral environmental initiatives by firms and industry associations ("corporate environmentalism"); (ii) negotiated agreements between government agents and firms or industry associations; and (iii) environmental programs designed by government agents to induce voluntary participation (Carraro and Lévêque, 1999; Segerson and Li, 1999).

${ }^{3}$ Examples include Project XL in the United States (Davis and Mazurek, 1996), and the many agreements negotiated under the Dutch National Environmental Policy Plan (CEC, 1996).

${ }^{4}$ For discussions of the use of regulatory threats to induce voluntary participation, see Goodin (1986), Lévêque and Nadaï (1995), Segerson and Miceli (1998, 1999), and Maxwell, et al. (2000).

${ }^{5}$ For recent surveys of the literature on voluntary approaches, see Segerson and Li (1999) and Khanna (2001).

${ }^{6}$ The policy approach examined here is similar to the provision point mechanism under which a public good is provided if and only if voluntary contributions are sufficient to cover the cost of providing the good (see, for example, Bagnoli and Lipman, 1989; Bagnoli and McKee, 1991; Marks and Croson, 1999; Rondeau, et al., 1999). We are indebted to Bill Schulze for noting this similarity.

${ }^{7}$ Although the two equilibrium concepts are identical in these simple examples, in a more general context they differ in an important respect, namely, that the self-enforcing equilibrium requires that the coalition be profitable while the concept of a Nash equilibrium does not have a comparable requirement for individuals. To illustrate the importance of this distinction, consider the example above where the collective target is set at 10 rather than 16. In this case, it is easily shown that the only Nash equilibrium is (NP,NP). Yet, in this example, full participation is a self-enforcing equilibrium. The difference between this example and the examples in the text lies in the differences in profitability. In the examples in the text, when one firm participates and the other does not, the payoff to the participating firm is at least as high as the payoff he would have received under the tax. Thus, he is willing to meet the target unilaterally. However, if only one firm were to participate when the target is set at 10 , his payoff would be lower than under the tax. Thus, if one firm "defects", the remaining coalition (of one) will dissolve because it is no longer profitable, making the first firm worse off than if he were to stay in the coalition. Recognizing this, the first firm will not defect and the full-participation equilibrium will be self-enforcing. See more detailed discussion below.

${ }^{8}$ It is interesting to note that introducing heterogeneity does not necessarily allow us to predict which firm will participate and which will not. As a simple example to illustrate this point, consider a case where the profit functions of the two firms are given by $\pi_{1}\left(e_{1}\right)=100-\left(10-e_{1}\right)^{2}$ and $\pi_{2}\left(e_{2}\right)=100-\left(12-e_{2}\right)^{2}$ and the regulator seeks to reduce emissions to 18 units. In this case, firm 1 has a lower marginal cost of abatement than firm 2. Yet, both (P,NP) and (NP,P) are Nash equilibria. At one equilibrium only the low cost firm participates while at the other equilibrium only the high cost firm participates.

${ }^{9}$ Both Maxwell, et al. (2000) and Millock and Salanié (2000) consider only full participation equilibria.

${ }^{10}$ See, for example, Segerson and Miceli (1998) and Segerson and Dawson (2001). 


\begin{abstract}
${ }^{11}$ Because our interest is in the design of environmental policy, we focus on regulatory threats as a motivation for participation in a VA and ignore any reputational gains or any gains that might result from appealing to "green consumers". As noted in the Introduction, these gains provide a potential motivation for "green production" that is independent of any government policy (see, for example, Arora and Gangopadhyay, 1995).

${ }^{12}$ This is in contrast to the literature on international environmental agreements (e.g., Carraro and Siniscalco, 1993; Barrett, 1994; Becker and Easter, 1999), which is generally concerned with global pollutants. In these models, all countries benefit directly from both their own abatement and the abatement of other countries.
\end{abstract}

${ }^{13}$ Note that if $E=0$, i.e., if the government seeks to ban emissions entirely, then even under a tax policy that meets the target the firms will make no tax payment (since there will be no emissions). In this case, there is no benefit to the firms from meeting the target voluntarily rather than having the tax imposed.

${ }^{14}$ We do not consider a case where the regulator would impose a tax only on those firms that did not participate in the voluntary programs. Some voluntary programs are of this type, i.e., they allow individual firms to avoid a (higher) tax by participation in a voluntary program (Chidiak, 1999; Millock, 1999). Here we are interested in a case where the regulator treats the industry as a single entity. If imposed, the tax would apply to all firms. If it is not imposed, all firms (including those who do not participate in the voluntary program) avoid the tax. Note that such an approach requires monitoring of only aggregate emissions (perhaps through ambient monitoring) rather than the monitoring of each individual source.

${ }^{15}$ Although we do not specify a form for $P(Y)$, we assume throughout that its curvature, coupled with the curvature of the cost function given above, ensure that all second-order conditions and all stability conditions are satisfied.

${ }^{16}$ These are derived from the standard first order conditions, i.e., $P^{\prime}(Y) y_{i}+P(Y)-C_{y}\left(y_{i}, e_{i}\right)=0$ for all $i$, which are sufficient given the assumption in note 15 . Note that if the firm's cost function is strongly separable, i.e., if $C_{y e}=0$, then the optimal output choice will not depend on the emissions level.

${ }^{17}$ Using the envelope theorem, the first order conditions defining the optimal emissions levels become $P^{\prime}\left(Y^{t}(e)\right) y_{i}^{t}(e)\left\{\Sigma_{j \neq i} \partial y_{j}^{t} / \partial e_{i}\right\}-C_{e}\left(y_{i}^{t}(e), e_{i}\right)-t=0$ for all $i$.

${ }^{18}$ For simplicity, we assume that the failure of the VA is detected and the tax is imposed instantaneously. In a two-period model in which detection occurs in the first period and the tax is imposed in the second period, the total payoffs would depend on the discount rate. See Millock and Salanié (2000) for a multiperiod model of VAs.

${ }^{19}$ Since the group of participants collectively agrees to ensure that the target is met, it might seem more appropriate to assume that they cooperate in their choice of output levels as well. However, in many countries such cooperation in the output market would be illegal under anti-trust laws. For this reason, we assume that all firms, including all participating firms, act non-cooperatively when choosing output.

${ }^{20}$ With identical firms, this is the most efficient allocation of emissions across the set of participating firms. It is also the allocation that would result from joint profit maximization or Nash bargaining by participating firms.

${ }^{21}$ Bars over variables indicate that the firm takes these variables as given.

${ }^{22}$ The corresponding first order condition is similar to the condition given in note 17 with the tax set equal to zero.

${ }^{23}$ Note that, if both the emissions cap and the number of participating firms are sufficiently low and the unconstrained level of emissions is sufficiently high, it may not be possible for an arbitrary number of 
participating firms to ensure that the aggregate target is met. For example, if $\mathrm{N}=10$ and $\mathrm{e}_{0}=10$, an aggregate emissions cap of 50 could not be met at any participation rate less than or equal to $50 \%$, since $e_{p}$ would be less than zero. Thus, for an arbitrary participation rate, a voluntary approach may not even be feasible. However, we show below that an equilibrium with a successful voluntary approach always exists, and it must, by definition, be feasible (i.e., have $\mathrm{e}_{\mathrm{p}} \geq 0$ ).

${ }^{24}$ If there is a fixed cost $\mathrm{F}$ associated with joining the voluntary program, then the condition for profitability would become $\pi_{p}^{*}\left(N_{p}\right)-F \geq \pi_{t}^{*}$. This would increase the minimum participation level defined below, but, with the appropriate changes in the subsequent definitions, would not otherwise change the qualitative results.

${ }^{25}$ As in the stable cartel literature, we do not consider the possibility of transfers between participating and non-participating firms. Some IEA studies allow this kind of transfer (Carraro and Siniscalco, 1993; Botteon and Carraro, 1997). However, transfers seem unlikely in our context.

${ }^{26}$ A full participation equilibrium would only be self-enforcing if the tax savings from meeting the target voluntarily were sufficiently small that free-riding by even one firm would make the voluntary approach unprofitable. This is more likely to occur when the number of firms in the industry is small. See the example discussed in note 7 .

${ }^{27}$ This occurs when $N_{p}<N-\left(E / e_{n}\right)$ so that $e_{p}<0$.

${ }^{28}$ Note that the example in Figure 2 satisfies this condition while the example in Figure 1 does not.

${ }^{29}$ When $N_{p}{ }^{*}=N$, the profit differential for all firms is simply their tax savings, since all firms undertake the same amount of abatement under the voluntary approach as under the tax.

${ }^{30}$ Social costs include only the abatement costs incurred by the firms. They do not include tax payments, which are simply a transfer from firms to the government/society.

${ }^{31}$ With a linear profit function, aggregate profits are independent of the allocation of abatement across firms.

${ }^{32}$ Proposition 6 identifies a distortion that results when the target is met voluntarily by a subset of firms in the industry. With imperfect competition in the output market, a second distortion exists as well. A full welfare comparison between the two policy approaches requires consideration of not only the different aggregate abatement costs but also the different aggregate output levels under the tax and voluntary approach. Under separability $\left(C_{y e}=0\right)$, aggregate output is the same under the two policies. However, without separability the two can be different. If the voluntary approach leads to less output because of higher cost, this would exacerbate the efficiency loss that stems directly from the inefficient allocation of abatement across firms.

${ }^{33}$ By first-best, we mean a regulation that provides the flexibility for each firm to achieve its emission reductions in the least cost way (such as a performance standard) and ensures an efficient allocation across firms. It is well-known, however, that regulation does not provide efficient long-run entry/exit incentives. See, for example, Baumol and Oates (1988).

${ }^{34}$ In contrast, if the regulator threatens imposition of an inefficient regulation, ${ }^{34}$ both society and the industry can benefit from use of the voluntary approach. Segerson and Dawson (2001) show that under the threat of the imposition of a regulation that is not fully efficient (e.g., one that does not allow the firm full flexibility in determining how the standard will be met), the total social cost of meeting an exogenous environmental quality standard will always be lower under the voluntary approach than under the regulation, even though in equilibrium there will be less than full participation.

${ }^{35}$ Nyborg (2000) notes that lobbying for the Norwegian voluntary agreements regarding waste packaging 
was a reaction to a real and credible threat of imposition of a packaging tax.

${ }^{36}$ This assumes that there is no compensating efficiency gain in the output market from a sufficiently large increase in output. 